\title{
Análise Comparativa do desempenho de concretos com adições minerais quanto à corrosão de arma- duras por íons cloretos
}

Pinheiro, H. F.

Escola Politécnica de Pernambuco Universidade de Pernambuco 50.720-001 - Recife, Brasil hugoofp@gmail.com

\author{
Monteiro, E. C. B. \\ Escola Politécnica de Pernambuco \\ Universidade de Pernambuco \\ 50.720-001 - Recife, Brasil \\ nana.monteiro@uol.com.br
}

Resumo Neste trabalho, procurou-se avaliar o comportamento de concretos produzidos com adições minerais, quanto à corrosão das armaduras sob a ação de cloretos livres. Realizaram-se ensaios de absorção capilar, absorção por imersão e ensaio acelerado de corrosão, de modo a avaliar de forma comparativa as adições utilizadas. Para cada adição foram feitos corpos de prova, variando a relação água/cimento $(0,4$ e 0,7), o tipo e o teor da adição. Ao longo dos ensaios de absorção capilar e absorção por imersão, as grandezas medidas foram: massa dos corpos de prova (M) e Variação da massa (Mv). $O$ procedimento adotado possibilitou analisar de forma comparativa a capacidade de absorção de líquidos. E no ensaio acelerado de corrosão, a grandeza medida foi:o potencial de corrosão. Desse modo, pode-se concluir que os corpos de prova com adição de 7\% de Sílica, com tempo de cura de 28 dias e relação água/cimento 0,4, foram os que apresentaram menor absorção de água, por capilaridade e imersão, e, portanto, os que apresentaram um melhor desempenho contra os ions cloretos..

\footnotetext{
Abstract In this work, we tried to evaluate the behavior of concrete made with mineral additions, the corrosion of the reinforcement under the action of free chlorides. There were essays of capillary absorption, absorption by immersion and accelerated assays of electrochemical corrosion, in order to evaluate comparatively the additions used. For each addition were made concrete specimens, varying the ratio water/cement (0.4 and 0.7), the type and content addition. Over the capillary absorption and absorption by immersion tests, the measured quantities were: mass of the concrete specimens (M) and Variation of mass $(M v)$. The procedure adopted allowed a comparative analysis of the ability to absorb liquids. And in the accelerated corrosion test, the quantity measured was: the potential for corrosion. So, we can conclude that the concrete specimens with the addition of $7 \%$ Silica, with cure time of 28 days and water / cement ratio 0.4, presented the lowest water absorption by capillarity and immersion and therefore, those who performed better against the chloride ions.
} 


\section{Introdução}

Existe uma preocupação constante no meio cientifico com a durabilidade do concreto armado. Devido a muitos casos que apresentam problemas estruturas, funcionais e de estética. Sendo a corrosão da armadura, uma das mais freqüentes e a que apresenta maior risco a segurança. Quando exposto a corrosão, o concreto armado tem sua vida útil reduzida, por esse ser um mecanismo que afeta sua durabilidade. Sérios danos a estrutura aparecem em forma de fissuras, perda de aderência, decaimento do cobrimento e redução da seção.

Esse Fenômeno tem grande incidência em todo o país, principalmente Pernambuco. Andrade (1997) em levantamento realizado no estado de Pernambuco constatou que a corrosão das armaduras é responsável pela maior parte da degradação das estruturas em concreto, sendo responsável por $62 \%$ dos casos de manifestações patológicas registradas nas edificações. Nince (1996), também pesquisando a incidência de manifestações patológicas em estruturas de concreto na região Centro-Oeste, encontrou a maior percentagem de incidência para a corrosão das armaduras de $30,1 \%$ em Brasília. Devido aos inúmeros casos de estruturas afetadas em todo o país, a corrosão das armaduras tem sido um grande problema na construção civil.

As armaduras das estruturas do concreto têm como camada protetora a cobertura de concreto. Que devido a sua elevada alcalinidade. Cria-se uma fina película passiva, que garante a proteção à corrosão. Entretanto essa relação de equilíbrio pode ser alterada quando o $\mathrm{pH}$ do concreto é reduzido, por carbonatação ou pela ação de ação de cloretos livres. Quando ocorre desequilíbrio, ocorre o fenômeno de despassivação da armadura. Esse fenômeno marca o início da fase de propagação da corrosão, e já se observa as manifestações típicas do fenômeno de corrosão. A carbonatação e os cloretos freqüentemente agem simultaneamente nas estruturas, ocasionando um efeito adicional na corrosão principalmente na fase de propagação (ALONSO \& ANDRADE, 1988, MONTEIRO, 1996). São cada vez mais empregadas técnicas de proteção a armadura do concreto. Visando o aumento da durabilidade e da sua vida útil. O uso de aditivos, como sílica e metacaulim, para diminuir os poros e assim a permeabilidade de agentes agressivos associado a alterações na relação água/cimento e no tempo de cura podem evitar o surgimento de patologias prematuras aumentando as estimativas de vida útil da estrutura.

\section{Procedimento Experimental}

\subsection{Materiais Utilizados}

Foram moldados corpos de prova, prismáticos e cilíndricos com os seguintes materiais: Cimento Portland
(CP II Z-32), areia oriunda da região e adições minerais (Sílica e Metacaulim).

\subsection{Metodologia Utilizada}

As séries dos corpos-de-prova estão descritas Tabela 1.

Tabela 1 - Denominação das séries de ensaios

\begin{tabular}{|c|c|c|c|c|}
\hline Séries & Adição & $\begin{array}{c}\text { Teor } \\
\text { de } \\
\text { adição }\end{array}$ & Traço & A/Ag \\
\hline 01 & S/ adição & $0 \%$ & $1: 0: 1,3$ & 0,4 \\
\hline 02 & S/ adição & $0 \%$ & $1: 0: 3$ & 0,7 \\
\hline 03 & Sílica & $7 \%$ & $0,93: 0,07: 0,6$ & 0,4 \\
\hline 04 & Sílica & $7 \%$ & $0,93: 0,07: 3,0$ & 0,7 \\
\hline 05 & Metacaulim & $15 \%$ & $0,85: 0,15: 0,3$ & 0,4 \\
\hline 06 & Metacaulim & $15 \%$ & $0,85: 0,15: 3,0$ & 0,7 \\
\hline
\end{tabular}

*Traço em massa

Os corpos-de-prova de presente trabalho foram cilíndricos, confeccionados nas dimensões $5 \times 10 \mathrm{~cm}$, e prismáticos, confeccionados nas dimensões de $60 \times 80 \mathrm{x}$ $25 \mathrm{~mm}$, com duas barras de $5.0 \mathrm{~mm}$ de diâmetro e $100 \mathrm{~mm}$ de comprimento. Para cada série foram feitos 6 corpos de prova prismáticos e 6 cilíndricos, sendo 3 com relação $\mathrm{a} / \mathrm{AC} 0,4$ e $3 \operatorname{com} 0,7$.

Para os ensaios acelerados de penetração de íons cloreto, foram utilizados corpos de prova, prismáticos. Para esse tipo de ensaio, foi utilizado a condição de imersão parcial em $\mathrm{NaCl}$ com semi-ciclos de secagem e imersão parcial, proposto por Monteiro (1996), pois além do transporte dos agentes agressivos por absorção capilar, permite o ingresso de cloreto por difusão.

Tabela 2 - Ensaio Acelerado de Cloretos

\begin{tabular}{|c|c|c|}
\hline SEMI-CICLO & CONDIÇÕES & DURAÇÃO \\
\hline Secagem & Estufa & 5 dias \\
\hline Umectação & $\begin{array}{c}\text { Parcialmente } \\
\text { submerso }\end{array}$ & 7 dias \\
\hline
\end{tabular}

Os corpos de prova, no ciclo de secagem, ficam dispostos em estufa ventilada, na temperatura de $50^{\circ} \mathrm{C}$, por 5 dias (Figura 4.1). No final os corpos de prova são pesados e são feitas as medições de potencial de corrosão. 


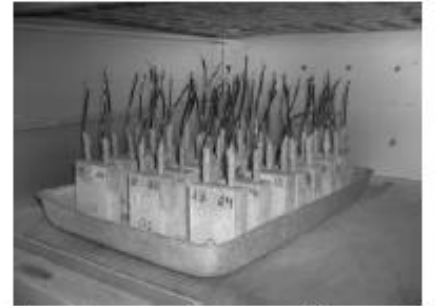

Figura 2.1 - Corpos de prova disposto em estufa

Já no ciclo de umectação, os corpos de prova são mantidos na condição de parcialmente imerso, com o nível da solução, de $5 \% \mathrm{NaCl}$, do recipiente que corresponde à metade da altura da área de exposição das barras (Figura 4.2). No final, são pesados e são feitas as medições de potencial de corrosão

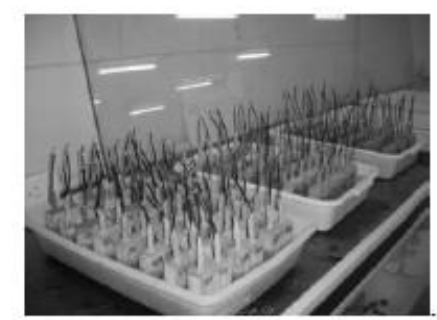

Figura 2.2 - Corpos de prova imerso em solução de $5 \% \mathrm{NaCl}$

O potencial de corrosão (Ecorr) é considerado um indicador de deterioração e avalia os aspectos termodinâmicos à corrosão. A norma ASTM C - 876/(1991) associa uma probabilidade superior a $95 \%$ de corrosão para valores de potenciais inferiores a $-350 \mathrm{mV}$, para eletrodo de cobre / sulfato de cobre.

O ensaio de Absorção por imersão seguiu a NBR 9778 (ABNT, 1997). Para o ensaio foram usados corpos de provas cilíndricos. Que foram dispostos em estufa, na temperatura de $100^{\circ} \mathrm{C}$, até atingir constância de massa. Após retirados da estufa, foram resfriados em ambiente de laboratório por $24 \mathrm{~h}$. Em seguida foram pesados e imersões em água a um nível de $20 \mathrm{~cm}$ (Figura 2.3), que foi mantido por todo o ensaio, 30 dias. Os corpos de prova foram pesados diariamente.

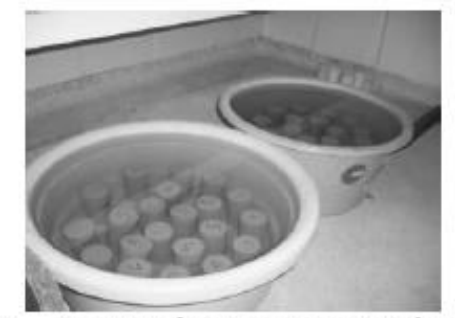

Figura 2.3 - Corpos de prova em ensaio de imersão

O ensaio de Absorção por capilaridade seguiu a NBR 9779 (ABNT, 1987). Para o ensaio foram usados corpos de provas cilíndricos, que foram dispostos em estufa, $100^{\circ} \mathrm{C}$, até atingir constância de massa. Após retirados da estufa, foram resfriados em ambiente de laboratório por $24 \mathrm{~h}$. Em seguida foram pesados, e dispostos em recipientes com água a nível constante de $5 \mathrm{~mm}$ (Figura 2.4), que foi mantido durante todo o ensaio, por coesões de água quando necessário. $\mathrm{O}$ ensaio deve duração de 30 dias, e os corpos de prova foram pesados diariamente.

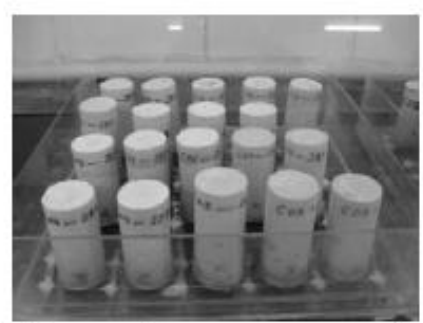

Figura 2.4 - Corpos de prova em ensaio de absorção por capilaridade

\section{Resultados}

\subsection{Materiais Utilizados}

A figura 3.1 apresenta os resultados do potencial de corrosão para os corpos de prova de Referência com relação água/cimento 04 , e 0,7 


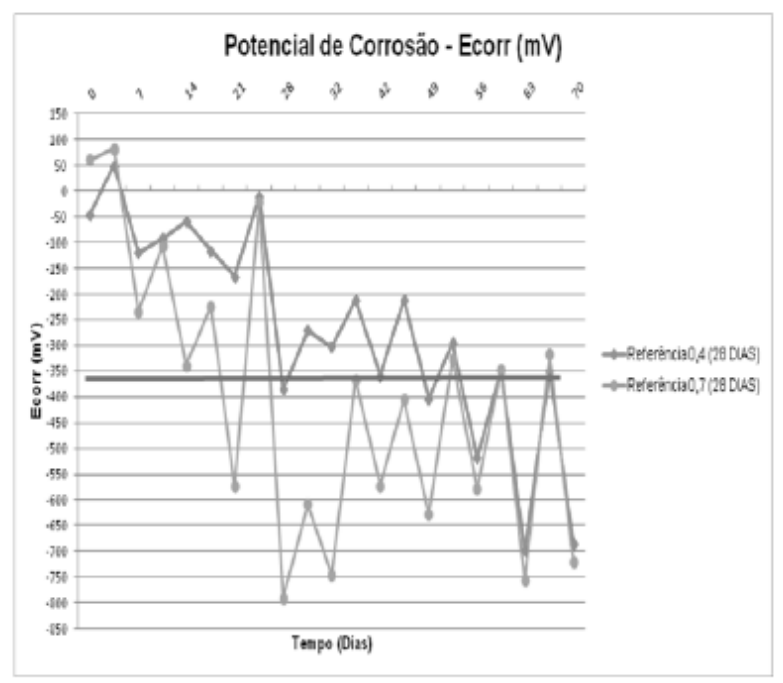

Figura 3.1 - Potencial de corrosão $(\mathrm{mV})$ para os corpos de prova Referência.

Conforme pode ser observado às armaduras da Referência 0,4 depassivaram após os 28 dias de ensaio, porém as armaduras de Referência 0,7, despassivaram após 21 dias atingindo patamar inferior a $-350 \mathrm{mV}$. O que demonstra a influência da relação água/cimento nos resultados.

A figura 3.2 apresenta os resultados de todos os corpos de prova para o ensaio de potencial de corrosão

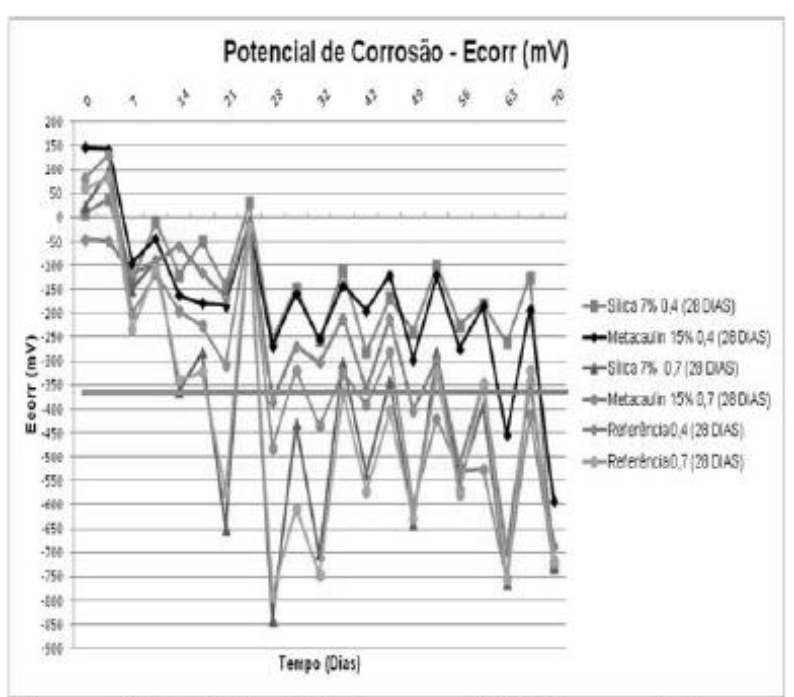

Figura 3.2 - Potencial de corrosão(mV) para todos os corpos de prova.

Como pode ser observado na Figura 3.2, os corpos de prova que apresentaram melhor desempenho foram os corpos de prova com adição de $7 \%$ de Sílica e relação água/cimento 0,4 .

\subsection{Ensaios de Absorção por imersãos}

A figura 3.1 mostra os resultados de absorção por imersão para os corpos de prova Referência, com 28 dias de cura e diferentes relações a/ag.

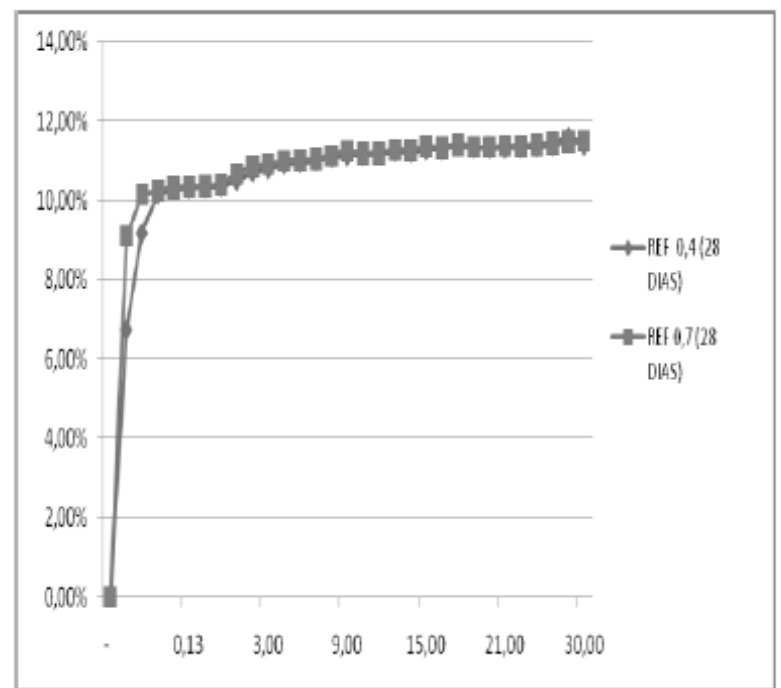

Figura 3.3 - Absorção por imersão para corpos de prova Referência.

Os resultados indicam que a variação na relação a/ag não tem influência significativa nos resultados de absorção de água por imersão para os corpos de prova de Referência em ambas as relações a/ag.

A figura 3.2 mostra os resultados de absorção por imersão para os corpos de prova com $15 \%$ de metacaulim e $7 \%$ de sílica. 


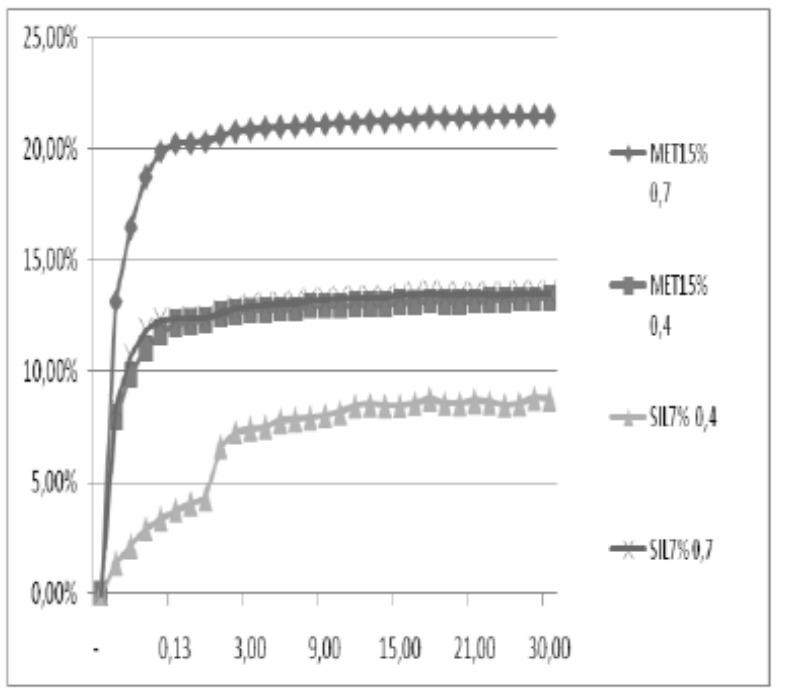

Figura 3.4 - Absorção por imersão para corpos de prova com adição de $15 \%$ de Metacaulim e de $7 \%$ de Sílica

\subsection{Ensaio de absorção por capilaridade}

A figura 3.3 mostra os resultados de absorção por capilaridade para os corpos de prova Referência e diferentes relações água/agloemerante.

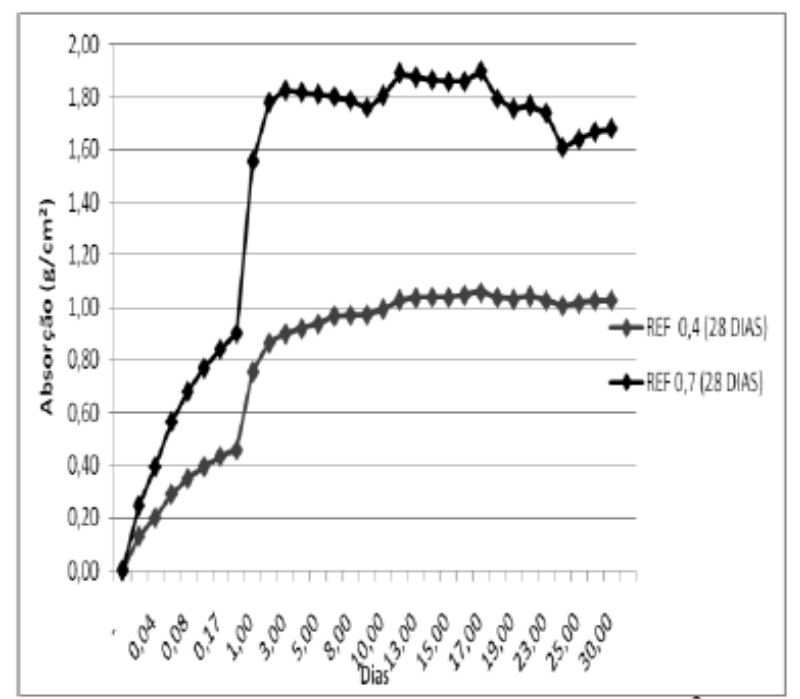

Figura 3.5 - Absorção por capilaridade $\left(\mathrm{g} / \mathrm{cm}^{2}\right)$ para corpos de prova Referência com tempo de cura de 28 dias e diferentes relações $\mathrm{a} / \mathrm{ag}$

Com base nos resultados apresentados na Figura 3.3, pode-se concluir que os corpos de prova de Referência com relação água/cimento 0,4 apresentaram menos absorção de água por capilaridade quando comparados com os corpos de prova de Referência com relação água/cimento 0,7 .
A figura 3.4 mostra os resultados, comparativos, de absorção por capilaridade para os corpos de prova de $15 \%$ metacaulim e de $7 \%$ séilica. Foi utilizado na comparação as realções a/ag 0,4 e 0,7, tanto para metacaulim quanto para sílica.

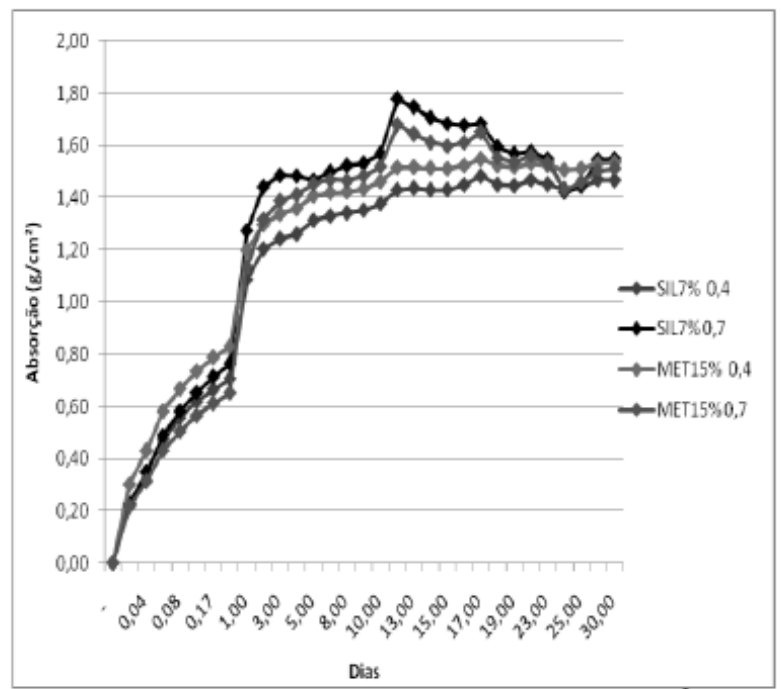

Figura 3.6 - Absorção por capilaridade $\left(\mathrm{g} / \mathrm{cm}^{2}\right)$ para corpos de prova com adição de $15 \%$ de Metacaulim e $7 \%$ de Sílica.

Nos resultados apresentados na Figura 3.4, a variação da relação a/ag e de adição, não influenciam significativamente nos resultados dos ensaios de absorção por capilaridade em corpos de prova com adição de $7 \%$ de Sílica e de $15 \%$ de Metacaulim. Ao fim do período de 30 dias verifico-se que os corpos de prova fator a/c 0,4 e $15 \%$ de Metacaulim absorveram $1,51 \mathrm{~g} / \mathrm{cm}_{2}$, enquanto que os corpos de prova fator a/c 0,7 absorveram $1,53 \mathrm{~g} / \mathrm{cm}_{2}$. Assim como nos corpos de prova de 7\% de Sílica, os corpos de prova fator a/c 0,4 absorveram 1,46 g para cada $\mathrm{cm}_{2}$ de superfície em contato com a água, enquanto que os corpos de prova fator a/c 0,7 absorveram $1,55 \mathrm{~g} / \mathrm{cm}_{2}$.

\section{Discussão dos Resultados}

\subsection{Absorção de água por capilaridade}

O índice de absorção capilar de um estrutura esta relacionado diretamente Às características do concreto que influenciam na capacidade de proteção das armaduras contra o fenômeno da corrosão.

A porosidade e permeabilidade indicam as condições da pasta do concreto referente à entrada de agentes agressivos até chegar à armadura através dos mecanismos de transporte. 
Os resultados obtidos neste ensaio indicam que a relação a/ag interferiu de maneira pouco significativa. Mesmo assim, os corpos de provas com relação água/cimento 0,4 obtiveram menor absorção que os de relação 0,7 devido a menor quantidade de vazios existentes na estrutura.

Os resultados indicam que os corpos de prova com adição de $7 \%$ de Sílica, tempo de cura 28 dias e relação a/ag 0,4 foram os que apresentaram menor absorção de água por capilaridade, sendo considerado portanto, o material que apresentou melhores resultados para os ensaios de absorção de água por capilaridade.

\subsection{Absorção por imersão}

A absorção por imersão também esta ligada a porosidade e permeabilidade do concreto onde os corpos de prova de relação água/cimento 0,4 obtiveram menor absorção.

Os resultados indicam que os corpos de prova com adição de $7 \%$ de Sílica, tempo de cura 28 dias e relação a/ag 0,4 foram os que apresentaram menor absorção de água por imersão, sendo considerado, portanto, o material que apresentou melhores resultados para os ensaios de absorção de água por imersão.

\subsection{Evolução do potencial de corrosão $\left(\mathbf{E}_{\text {coor }}\right)$}

Como pôde ser observado na Figura 3.2, os corpos de prova que apresentaram melhor desempenho foram os corpos de prova com adição de $7 \%$ de Sílica e relação água/cimento 0,4 .

Observa-se que a Sílica teve melhor comportamento nos ensaios de absorção por capilaridade e imersão, mostrando que os corpos de prova com adição de Sílica apresentaram comportamentos de poros mais refinados, consequentemente, mais impermeáveis do que os corpos de prova com adição de metacaulim.

\section{Referências}

[1] ANDRADE, J. J. O. Durabilidade das estruturas de concreto armado: análise das manifestações patológicas nas estruturas no estado de Pernambuco (Dissertação de Mestrado). Universidade Federal do Rio Grande do Sul, 1997

[2] NINCE, A. A. Levantamento de Dados sobre a Deterioração de Estruturas na Região CentroOeste. Dissertação de Mestrado, Brasília, UnB, 1996
[3] ALONSO, M. C. ; ANDRADE, C. Corrosion of steel reinforcement in carbonated mortar containing chloride. Advanced Cement Research, v.1, 1988.

[4] MONTEIRO, E.C.B. Estudo da capacidade de proteção de alguns tipos de cimentos nacionais, em relação à corrosão de armaduras, sob a ação conjunta de CO2 e íons cloretos. 1996. 138p. Dissertação (Mestrado) - Departamento de Engenharia Civil, Universidade de Brasília. Brasília.

[5] AMERICAN SOCIETY FOR TESTING AND MATERIALS. Standard test method for half cell potential of uncoated reinforcing steel in concrete. ASTM C 876: 1991. Philadelphia: Annual Book of ASTM Standards.

[6] ASSOCIAÇÃO BRASILEIRA DE NORMAS TÉCNICAS - ABNT - NBR 9778. (1987) “Argamassa e concreto endurecidos - determinação da absorção de água por imersão - índice de vazios e massa específica". Rio de Janeiro.

[7] ASSOCIAÇÃO BRASILEIRA DE NORMAS TÉCNICAS. NBR 9779: Argamassa e concreto endurecidos - Determinação da absorção de água por capilaridade. Rio de Janeiro, 1995. 